\title{
Total Gross Tumor Volume Is an Independent Prognostic Factor in Patients Treated With Selective Nodal Irradiation for Stage I to III Small Cell Lung Cancer
}

Citation for published version (APA):

Reymen, B., Van Loon, J., van Baardwijk, A., Wanders, R., Borger, J., Dingemans, A-M. C., Bootsma, G., Pitz, C., Lunde, R., Geraedts, W., Lambin, P., \& De Ruysscher, D. (2013). Total Gross Tumor Volume Is an Independent Prognostic Factor in Patients Treated With Selective Nodal Irradiation for Stage I to III Small Cell Lung Cancer. International Journal of Radiation Oncology Biology Physics, 85(5), 1319-1324. https://doi.org/10.1016/j.jijrobp.2012.10.003

Document status and date:

Published: 01/04/2013

DOI:

10.1016/j.jijrobp.2012.10.003

Document Version:

Publisher's PDF, also known as Version of record

Document license:

Taverne

Please check the document version of this publication:

- A submitted manuscript is the version of the article upon submission and before peer-review. There can be important differences between the submitted version and the official published version of record. People interested in the research are advised to contact the author for the final version of the publication, or visit the DOI to the publisher's website.

- The final author version and the galley proof are versions of the publication after peer review.

- The final published version features the final layout of the paper including the volume, issue and page numbers.

Link to publication

\footnotetext{
General rights rights.

- You may freely distribute the URL identifying the publication in the public portal. please follow below link for the End User Agreement:

www.umlib.nl/taverne-license

Take down policy

If you believe that this document breaches copyright please contact us at:

repository@maastrichtuniversity.nl

providing details and we will investigate your claim.
}

Copyright and moral rights for the publications made accessible in the public portal are retained by the authors and/or other copyright owners and it is a condition of accessing publications that users recognise and abide by the legal requirements associated with these

- Users may download and print one copy of any publication from the public portal for the purpose of private study or research.

- You may not further distribute the material or use it for any profit-making activity or commercial gain

If the publication is distributed under the terms of Article 25fa of the Dutch Copyright Act, indicated by the "Taverne" license above, 


\title{
Total Gross Tumor Volume Is an Independent Prognostic Factor in Patients Treated With Selective Nodal Irradiation for Stage I to III Small Cell Lung Cancer
}

\author{
Bart Reymen, MD, ${ }^{*}$ Judith Van Loon, MD, PhD, * Angela van Baardwijk, MD, PhD,* \\ Rinus Wanders, MD, ${ }^{*}$ Jacques Borger, MD, PhD, * Anne-Marie C. Dingemans, MD, PhD, ${ }^{\dagger}$ \\ Gerben Bootsma, MD, PhD, ${ }^{\ddagger}$ Cordula Pitz, MD, PhD, ${ }^{\S}$ Ragnar Lunde, MD, $\|$ \\ Wiel Geraedts, MD, ${ }^{\top}$ Philippe Lambin, MD, PhD, ${ }^{*}$ and Dirk De Ruysscher, MD, PhD*,\#
}

\begin{abstract}
*Department of Radiation Oncology (MAASTRO clinic) and ${ }^{\dagger}$ Department of Pulmonology, GROW - School for Oncology and Developmental Biology, Maastricht University Medical Centre, Maastricht, The Netherlands; ${ }^{\ddagger}$ Department of Pulmonology, Atrium Medical Centre, Heerlen, The Netherlands; ${ }^{\circledR}$ Department of Pulmonology, Laurentius Hospital, Roermond, The Netherlands; "Department of Pulmonology, St Jansgasthuis, Weert, The Netherlands; "Department of Pulmonology, Orbis Medical Centre, Sittard, The Netherlands; and "University Hospital Leuven/ KU Leuven, Leuven, Belgium
\end{abstract}

Received May 3, 2012, and in revised form Sep 25, 2012. Accepted for publication Oct 2, 2012

\section{Summary \\ In this series of 119 patients with stage I to III small cell lung cancer who were treated with accelerated concurrent chemoradiation using selec- tive nodal irradiation based on positron emission tomog- raphy, less than $2 \%$ of patients experienced elective nodal failure. In multivariate analysis, total gross tumor volume appears to be the most important prognostic factor for survival.}

\begin{abstract}
Purpose: In non-small cell lung cancer, gross tumor volume (GTV) influences survival more than other risk factors. This could also apply to small cell lung cancer.

Methods and Materials: Analysis of our prospective database with stage I to III SCLC patients referred for concurrent chemo radiation therapy. Standard treatment was 45 Gy in 1.5-Gy fractions twice daily concurrently with carboplatin-etoposide, followed by prophylactic cranial irradiation (PCI) in case of non-progression. Only fluorodeoxyglucose (FDG)-positron emission tomography (PET)-positive or pathologically proven nodal sites were included in the target volume. Total GTV consisted of post chemotherapy tumor volume and pre chemotherapy nodal volume. Survival was calculated from diagnosis (Kaplan-Meier ).

Results: A total of 119 patients were included between May 2004 and June 2009. Median total GTV was $93 \pm 152 \mathrm{cc}(7.5-895 \mathrm{cc})$. Isolated elective nodal failure occurred in 2 patients $(1.7 \%)$. Median follow-up was 38 months, median overall survival 20 months (95\% confidence interval $=17.8-22.1$ months), and 2-year survival $38.4 \%$. In multivariate analysis, only total GTV $(P=.026)$ and performance status $(P=.016)$ significantly influenced survival.

Conclusions: In this series of stage I to III small cell lung cancer patients treated with FDG-PET-based selective nodal irradiation total GTV is an independent risk factor for survival. (c) 2013 Elsevier Inc.
\end{abstract}

Reprint requests to: Bart Reymen, MD, 6229 ET Maastricht, The Netherlands. Tel: +31 (0)88 44 55 666; Fax: +31 (0)88 4455 667; E-mail: bart.reymen@maastro.nl 


\section{Introduction}

Classic prognostic factors for survival in small cell lung cancer (SCLC) include stage, age, level of lactate dehydrogenase (LDH), time between start of any treatment to the end of radiation therapy (SER), male sex, N3 nodal status, and WHO performance score (WHO-PS) (1).

Clinicians intuitively accept that larger tumors are less likely to remain controlled. Gross tumor volume (GTV) is a fairly recent concept, which could not be investigated in the pre-computed tomography $(\mathrm{CT})$ era. Indeed, in the International Union Against Cancer (UICC) TNM classification, only the T-stage may include the 2-dimensional (2D) diameter of the primary tumor, but size of nodes or total GTV are not present (2).

In prognostic models concerning non-small cell lung cancer (NSCLC), GTV, together with the number of nodal stations, outweigh TNM stage $(3,4)$ Therefore we investigated the value of total GTV, defined as the volume of the primary tumor and the involved lymph nodes on a planning positron emission tomography (PET)-CT as a potential stratification factor in SCLC. Furthermore, we updated our results of selective nodal irradiation (SNI) based on PET-CT (5).

\section{Methods}

\section{Patient population}

Since 2003, patients treated at Maastro Clinic are collected in a prospective database.

We analyzed all patients with stage I to III SCLC referred for concurrent chemoradiation therapy from May 2004 until June 2009.

Patients had pathologically proven SCLC stage I to III according to UICC TNM classification version 6, excluding T4 disease due to malignant pleural or pericardial effusion (6). WHO-PS of 0 to 2 and adequate pulmonary function (forced expiratory volume at 1 second $\left[\mathrm{FEV}_{1}\right]$, carbonic oxygen diffusion capacity [DLCO] both $\geq 30 \%$ ), hematological, hepatic, and renal function were required. Patients with N3 disease (including contralateral supraclavicular and/or contralateral mediastinal nodes) were also treated radically.

\section{Staging}

All patients were staged by whole-body ${ }^{18}$ F-fluorodeoxyglucose (FDG)-PET scan (not in treatment position) and CT or magnetic resonance imaging (MRI) of the brain.

\section{Chemotherapy}

Standard chemotherapy in the region of the Integraal Kankercentrum Limburg consisted of carboplatin on day 1 and etoposide (120 $\mathrm{mg} / \mathrm{m}^{2}$ ) on days 1 to 3 for 5 cycles, repeated every 21 days. Carboplatin dose was based on the target AUC $(5 \mathrm{mg} / \mathrm{ml} / \mathrm{h}) \times$ (glomerular filtration rate $[\mathrm{GFR}]+25)$. GFR was calculated using the Cockroft-Gault formula. Standard dose-reduction rules applied.

\section{Radiation therapy}

Apart from the staging PET scan, a dedicated FDG-PET-CT scan in treatment position (supine, arms raised) was used for treatment planning in almost all patients 5 to 7 days before start of radiation therapy. From April 2006 onward (81 patients, 68\%), respiration- correlated CT (RCCT) images were acquired. When a planning PET was not available, the diagnostic PET was fused with the planning CT.

Patients were scanned from the cricoid to the second lumbar vertebra with $3 \mathrm{~mm}$-slices. Automated rigid registration based on mutual information of PET and CT images was followed by fusion using the Focal software (Computerized Medical Software [CMS], St Louis, MS). Contouring was done on the mid-ventilation images of the RC-CT. Treatment planning was performed on the $\mathrm{XiO}$ system (CMS), using a convolution and from May 2007 onwards a superposition algorithm. The GTV of the primary tumor was the post chemotherapy volume defined on the planning PETCT while for the lymph nodes, the pre chemotherapy extension was reconstructed to avoid previously involved nodal sites being left out of the planned target volume (PTV). Window settings were $\mathrm{W}=1700, \mathrm{~L}=-300$ (lung) and $\mathrm{W}=600, \mathrm{~L}=40$ (mediastinum). The nuclear medicine physician's pre chemotherapy PET report was used to locate tumor sites. PETnegative enlarged lymph nodes were not delineated. In case of confluent central masses, the part adjacent to the lung was considered the primary tumor, whereas the mediastinal extension was considered as nodal volume and delineated accordingly. The border between the 2 volumes was left up to the treating physician. GTV was expanded with $5 \mathrm{~mm}$ to create a clinical target volume (CTV), excluding vessels and esophagus. No elective nodal regions were delineated. CTV-to-PTV margin was $5 \mathrm{~mm}$ for the lymph nodes and $10 \mathrm{~mm}$ for the tumor.

Dose constraints for the organs at risk were: mean lung dose (MLD) of $19 \mathrm{~Gy} \pm 1 \mathrm{~Gy}$ (volume of both lungs minus GTV). The esophagus had no dose constraint. Three-dimensional (3D) conformal radiation therapy plans were constructed following the International Commission on Radiation Units and Measurements (ICRU) 50 guidelines using 6 or $10 \mathrm{MV}$ photons. The prescribed dose was 45 Gy in 30 fractions administered in 1.5-Gy fractions twice daily over 3 weeks with a minimal inter-fraction interval of 8 hours. Radiation therapy was started as soon as possible after the first chemotherapy to limit the "start of any therapy to the end of radiation therapy (SER)" time (7). No gating or breath hold was used, and treatment verification was done with routine (daily) electronic portal imaging dosimetry (8).

After the end of chemoradiation, patients with a WHO-PS $\leq 2$ were offered prophylactic cranial irradiation (PCI) to a dose of 25 Gy in 10 fractions in case of clinical nonprogression.

\section{Follow-up}

The radiation oncologist checked patients weekly during radiation therapy, and at 2 to 4 weeks after the end of treatment. Patients were followed until acute side effects subsided to grade 1 . Afterward the pulmonologist performed 3-monthly follow-up during the first year, 6-monthly from years 2 to 5 and yearly thereafter. Toxicity was recorded following CTCAE, version 3.0. A chest CT-scan or X-ray was acquired at each visit until progression. Overall survival was evaluated using the "Gemeentelijke Basis Administratie" (GBA) database $(5,9)$

\section{Statistical analysis}

Endpoints were patterns of failure, overall survival (OS), and progression-free survival (PFS). In-field failure was defined as recurrence in which more than $50 \%$ of the tumor volume was included in the original CTV. Out-of-field failure was defined as 
a recurrence for most part extending outside the original CTV. Elective nodal failure (ENF) was defined as out-of-field nodal recurrence in hilar, mediastinal or supraclavicular lymph nodes. Isolated ENF or local tumor failure was defined as ENF or local tumor failure without other sites of recurrence. Survival was calculated using SPSS, version 17.0, (Kaplan-Meier) from diagnosis until death.

Factors included in multivariate survival analysis were stage, age, level of LDH at diagnosis, SER, male sex, N3-status, WHOPS, and GTV (1). Total GTV comprised the total volume of nodes (pre chemotherapy) and tumor (post chemotherapy) defined on the planning PET-CT scan.

Median survival is expressed with the $95 \%$ confidence interval (CI), other results as mean \pm standard deviation (SD) and their range. Cox regression multivariate analysis was performed. A $P$ value of less than .05 was considered significant.

\section{Results}

\section{Patient characteristics}

From April 2004 until June 2009, 119 patients with stage I to III SCLC were referred to Maastro Clinic for concurrent chemoradiation therapy.

Patient characteristics are summarized in Table 1.

Patients were 41 to 85 years of age, with a median age of $66 \pm$ 8.8 years. All but 2 patients received carboplatin-etoposide. Both of these patients received carboplatin-paclitaxel instead: 1 patient because of synchronous ovarian cancer, and the other because of intolerance to etoposide.

Two patients (1.6\%) did not receive the planned dose of $45 \mathrm{~Gy}$ because of neutropenic sepsis; 1 patient died after 4 fractions (6 Gy), and 1 patient was hospitalized after $39 \mathrm{~Gy}$.

The median interval between the pathologic diagnosis of SCLC and start of treatment was $15 \pm 9.8$ days (0-47 days). The median interval between the first day of chemotherapy and start of radiation therapy was $20 \pm 13$ days (range, -5 to 82 days). The overall treatment time (OTT) of RT was $21 \pm 2.7$ days (1-32 days) with a median SER of $39 \pm 13.4$ days (8-100 days).

In all, 105 patients (88\%) received PCI. Reasons for not receiving PCI were progression $(5 / 14$, brain in $4 / 5)$, death $(5 / 14)$, refusal (2/14), $\mathrm{WHO}>2$ (1/14), and miscommunication (1/14).

\section{Patterns of failure}

One patient was lost to follow-up after 22 months. Median followup is $38 \pm 17$ months (22-84 months). A total of 76 patients (64\%) had disease progression at the time of analysis. Table 2 lists the frequency and patterns of relapse.

Eighteen patients (15\%) developed local tumor recurrence, which was out-of-field in 4 of 14 patients. One patient had a geographical miss; in retrospect, the CTV of the primary tumor had not been included in the PTV.

Distant metastases developed in 65 patients (55\%). In 14 patients (12\%), isolated brain metastases were the first site.

Thirty-nine patients had a nodal recurrence (32\%), mostly infield $(26 \%)$.

In 2 patients (1.7\%), an isolated ENF occurred. Sixteen months after treatment for a tumor with a single PET-positive node in region 6, 1 patient had a nodal recurrence in regions $2 \mathrm{~L}$ and $1 \mathrm{~L}$, which was re-treated with concurrent chemoradiation therapy. The
Table 1 Patient characteristics

\begin{tabular}{|c|c|}
\hline Characteristic & $\begin{array}{c}\text { No. }(\%) \\
\text { of patients* }\end{array}$ \\
\hline \multicolumn{2}{|l|}{ Sex } \\
\hline Male & $69(58)$ \\
\hline Female & $50(42)$ \\
\hline \multicolumn{2}{|l|}{ Age (y) } \\
\hline Median & $66( \pm 8.8)$ \\
\hline Range & 41-85 \\
\hline \multicolumn{2}{|l|}{ WHO-PS } \\
\hline 0 & $38(32)$ \\
\hline 1 & $64(54)$ \\
\hline 2 & 17 (14) \\
\hline \multicolumn{2}{|l|}{ UICC Stage } \\
\hline IA & $1(1)$ \\
\hline IB & $3(3)$ \\
\hline IIA & $5(4)$ \\
\hline IIB & $6(5)$ \\
\hline IIIA & $24(20)$ \\
\hline IIIB & $80(67)$ \\
\hline \multicolumn{2}{|l|}{ GTV (cc) } \\
\hline Median & $93( \pm 152)$ \\
\hline Range & $7.5-895$ \\
\hline \multicolumn{2}{|l|}{$\mathrm{N} 3$ subdivision } \\
\hline Supraclavicular nodes & $29(24)$ \\
\hline Contralateral supraclavicluar & $15(13)$ \\
\hline Contralateral hilar nodes & $10(8)$ \\
\hline \multicolumn{2}{|l|}{ Chemotherapy } \\
\hline Carboplatin-etoposide & 117 \\
\hline Carboplatin-Taxol & 2 \\
\hline \multicolumn{2}{|l|}{ SER } \\
\hline Median & $39( \pm 13)$ \\
\hline Range & $8-100$ \\
\hline$>30 \mathrm{~d}$ & $102(86)$ \\
\hline \multicolumn{2}{|l|}{ LDH } \\
\hline Normal & 86 \\
\hline Elevated ( $>$ upper limit of normal) & 33 \\
\hline \multicolumn{2}{|l|}{ Delivered dose of radiation therapy (Gy) } \\
\hline Median & $45( \pm 3.6)$ \\
\hline Range & $6-45$ \\
\hline \multicolumn{2}{|c|}{$\begin{array}{l}\text { Abbreviations: WHO-PS: World Health Organisation-Performance } \\
\text { Status; Gy = Gray; GTV = gross tumor volume; LDH = lactate } \\
\text { dehydrogenase; SER = start of any treatment to the end of radiation } \\
\text { therapy; UICC = Union Internationale Contre Cancer. } \\
* \text { Values in parentheses are percentages, except for age, which is } \\
\text { standard deviation. }\end{array}$} \\
\hline
\end{tabular}

other patient had had PET-positive nodes in the left hilum and region 5. The recurrence occurred after 31 months in region $4 \mathrm{R}$. This node was not pathologically validated, because the patient was diagnosed simultaneously with an inoperable pelvic recurrence of ovarian cancer, which was uncontrolled and was only treated palliatively.

\section{Survival}

At a median follow-up of $38 \pm 17$ months (22-84) the median actuarial OS was $20 \pm 1$ months (95\% confidence interval $[\mathrm{CI}]=17.9-22.1$ months) with a 2 -year OS of $39 \%$ and a 3 -year 
Table 2 Patterns of relapse

\begin{tabular}{lc}
\hline \multicolumn{1}{c}{ Recurrence } & $\begin{array}{c}\text { No. }(\%) \\
\text { of patients }\end{array}$ \\
\hline None & $43(36)$ \\
Local tumor failure & $18(15)$ \\
Local failure + regional/distant failure & $16(13)$ \\
Isolated local tumor failure & $2(2)$ \\
In-field tumor failure & $13(11)$ \\
Regional nodal failure & $39(32)$ \\
Nodal + local/distant failure & $33(27)$ \\
Isolated nodal failure & $6(5)$ \\
Isolated elective nodal failure & $2(2)$ \\
Distant failure & $65(55)$ \\
Distant + local/regional failure & $28(24)$ \\
Isolated distant failure & $37(31)$ \\
Isolated brain recurrence & $14(12)$ \\
\hline Numbers between parentheses are percentages. Location of relapses \\
were assessed with CT.
\end{tabular}

OS of $25 \%$ (Fig. 1). Median actuarial PFS was $14 \pm 0.7$ months (95\% CI $=12.5-15.4$ months). with a 2 -year PFS of $32 \%$.

\section{Factors associated with survival}

On univariate analysis factors influencing survival were GTV $(P=.008)$ and WHO-PS $(P=.023)$. Contralateral hilar or supraclavicular nodes did not have a significant impact on OS $(P=.314)$.

Multivariate analysis was performed considering GTV a continuous variable.

The only factors showing a significant influence on OS were total GTV $(P=.016$, hazard ratio of 1.002 per cubic centimeter [cc]) and WHO-PS $(0 / 1$ vs 2$)(P=.026)$. A threshold GTV could not be established. Stage (I/II vs III), N-status (N3 vs other), SER ( $\leq 30$ days vs $>30$ days), sex (male vs female), age ( $<70$ years vs $\geq 70$ years) and LDH (normal vs elevated) did not gain significance. Table 3 shows the results of the univariate and multivariate analysis.

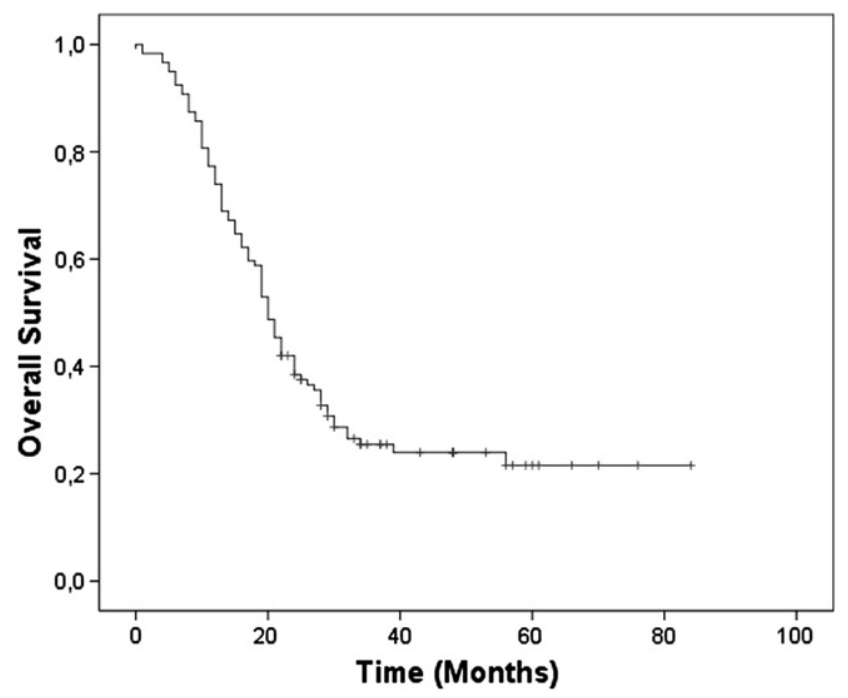

Fig. 1. Overall survival, Kaplan-Meier curve. Actuarial overall survival of 119 patients.
Table 3 Impact of prognostic factors on overall survival (OS)

\begin{tabular}{lccc}
\hline \multirow{2}{*}{ Factor } & \multirow{2}{*}{$\begin{array}{c}\text { Univariate } \\
\text { analysis }\end{array}$} & \multicolumn{2}{c}{ Multivariate analysis } \\
\cline { 3 - 4 } & $P$ value & Hazard ratio \\
\hline Total GTV & $\mathbf{0 . 0 0 8}$ & $\mathbf{. 0 1 6}$ & $\mathbf{1 . 0 0 2}$ (per cc) \\
WHO-PS & $\mathbf{0 . 0 2 8}$ & $\mathbf{. 0 2 6}$ & $\mathbf{0 . 5 1 2}$ \\
Stage & 0.284 & .631 & NS \\
Age & 0.976 & .364 & NS \\
Gender & 0.810 & .668 & NS \\
LDH & 0.103 & .529 & NS \\
N-status & 0.236 & .359 & NS \\
SER & 0.468 & .362 & NS \\
\hline
\end{tabular}

Abbreviations: GTV $=$ gross tumor volume; $\mathrm{LDH}=$ lactate dehydrogenase; $\mathrm{N}$-status $=$ nodal status $(\mathrm{N} 3$ vs N0-2); SER = interval between start of any treatment and the end of radiation therapy; WHOPS $=$ World Health Organisation-Performance Status.

\section{Toxicity}

Esophagitis grade 3 (necessitating hospitalization and/or feeding tube) was the most frequent severe reaction, occurring in 22 patients (19\%) but subsiding to grade 1 or less in all but 1 patient 3 months after radiation therapy. Eight patients (7\%) developed grade 3 dyspnea during or shortly after radiation therapy, which was still present after 3 months in 1 patient with severe chronic obstructive pulmonary disease (COPD; DLCO, 32\%) and grade 2 dyspnea already at baseline.

Cough reached grade 3 in 3 patients during treatment $(2.5 \%)$. In 1 patient, this was due to a severe pneumonia requiring IV antibiotics. In all patients, this subsided to grade 2 or less at 3 months after radiation therapy.

At baseline, $46 \%$ of patients presented without dyspnea, whereas 3 months after treatment, $72 \%$ had no dyspnea.

\section{Discussion}

In the past years, the interest of researchers in selective nodal irradiation in SCLC has grown. Already starting from the late 1980 s, smaller radiation ports were used in trials to decrease the acute toxicity of emerging combined modality treatments (10). However, omission of elective nodal irradiation was pioneered by De Ruysscher et al, whose first attempt of CT-based SNI yielded an elective nodal failure rate of $11 \%$, probably due to the low sensitivity and specificity of CT in mediastinal nodes of SCLC (11).

Based on the higher accuracy of PET scans in detecting malignant mediastinal nodes, a subsequent trial on PET-based SNI in 60 patients with stage I to III SCLC reported isolated nodal failure in only $3 \%$ of patients, comparable to results in NSCLC (5, $11,12)$. Shirvani et al confirmed this in their retrospective analysis of 60 patients treated with PET-based intensity modulated radiation therapy (IMRT) concurrently with platinum-based chemotherapy, reporting an isolated elective nodal failure (ENF) rate of $2 \%$ (13). Our present series is a continuation of the work by Van Loon et al, expanding her series of 59 patients (60 patients, excluding 1 patient referred for sequential chemo radiation in that series) with the next consecutive 60 patients treated following the same methods. We deliberately kept our follow-up at a minimum of 22 months to ensure robust survival data. Indeed, the effects of 
a change in treatment regimen on local control will start affecting overall survival only after an average of 2 years $(14,15)$.

Isolated ENF occurred in only 2 patients, which is remarkably similar to the frequency noted in the Shirvani et al article and which strengthens the case for PET-based irradiation of SCLC (13),

We defined an isolated elective nodal failure as a nodal relapse occurring in an area that would have been included in the elective CTV in absence of other sites of disease as this represents in our view a potential missed cure by omitting elective nodal irradiation (ENI).

An often-heard criticism of SNI is the fact that there is still a high number of ENF detected along with distant metastases (16). In this case the question arises as to whether prevention of the nodal recurrence would have prevented the metastases. Fifteen patients with out-of-field ENF were diagnosed simultaneously with distant metastases. Ten of these patients had simultaneous infield relapses. This means that 5 patients $(4.2 \%)$ had a combination of ENF and distant metastases, diagnosed at a median of 14 months. Whether these metastases would have been prevented by ENI is a question that can be answered only by a large randomised trial. However, because of the small numbers at risk and the high incidence of distant relapse, a significant survival benefit of ENI, keeping the rest of the treatment (RT dose and chemotherapy) constant, would be difficult to establish.

The low loco regional control rate remains worrisome. Fifteen percent of patients experienced a local tumor recurrence, and infield nodal relapses occurred in $26 \%$ of cases. This is in line with the respective $36 \%$ and $34 \%$ local failure rate reported by Turrisi and Watkins, but contrasts with the $8 \%(5 / 60)$ in-field locoregional relapse rate reported by Shirvani $(13,14,17)$.

Comparison of our series with the Shirvani et al paper is difficult in this respect. Their shorter median follow-up time of 26 months inevitably leads to a larger confidence interval in results. Of our patients, $46 \%$ had N3 disease versus $37 \%$ in their series. Apart from using IMRT opposed to our 3D conformal radiation therapy, they also used radiation therapy schedules different from the Turrisi schedule in $32 \%$ of their patients, with total doses ranging up to $63.8 \mathrm{~Gy}$, which could obviously affect loco regional control, as is the subject of 2 ongoing EORTC (CONVERT) and Intergroup (CALGB 30610, RTOG 0538, NCT00632853) trials (13).

As in other series the predominant pattern of recurrence is the development of distant metastases, implying an important role for more effective systemic therapy. During the studied time period, carboplatin held the personal preference of an influential staff member of the university hospital, which was adopted throughout the region. Recently our region has switched to cisplatin instead of carboplatin, although a recent meta-analysis suggests equivalent tumor outcome with either regimen (18).

To our knowledge, this is the first time that total GTV has been shown to affect overall survival in SCLC more than classical factors such as age, gender, $\mathrm{LDH}$, and stage. This result is in line with findings in NSCLC $(3,4)$. Why age, gender, LDH, or stage were not even significant on univariate analysis is not clear, but might also be attributable to sample size or for some parameters because of their relatively narrow range. We could not define a threshold GTV for stratification. In the present series of patients, $72 \mathrm{cc}$ comes closest to separation into prognostic groups with a $P$ value of .06 for overall survival. The inclusion of more patients might solve this problem, but as the definition of GTV in our protocol is still somewhat dual, in this article it is best treated as a continuous variable.

Whether the impact of total GTV represents the sheer number of cells to be eradicated, a higher rate of hypoxia in larger tumor sites, or a more aggressive phenotype can not be deducted from current data. Another explanation might be the fact most of our patients received 1 cycle of chemotherapy before starting radiation therapy. By using the post chemotherapy GTV for the primary tumor, a smaller volume could thus be a surrogate for response to chemotherapy.

Whichever mechanism underlies the influence of GTV on survival, future trials should take the total GTV into account as a stratification factor.

We confirm the detrimental impact of a poor performance status at diagnosis: patients with WHO-PS of 0-1 had a 2-year OS of $42 \%$, versus those with a WHO-PS of 2 who had an OS of $12 \%$. Only 2 of 17 patients presenting with a WHO-PS of 2 survived for more than 2 years, both being alive, however, at 4 years after diagnosis. The exclusion of patients from radical treatment solely based on a WHO-PS of 2, remains debatable, but this parameter should certainly be incorporated into prognostic models.

There are some drawbacks to this study. This is a monocentric series that was prospectively collected but was retrospectively evaluated for toxicity and tumor status. However, follow-up in our region is performed according to strict guidelines with good compliance. Survival data were collected directly from the central Dutch GBA database, which guarantees accurate results. Prospective trials using PET-CT-based selective nodal irradiation are not expected in the near future. The CONVERT trial uses selective nodal irradiation, but does not require PET-CT scans for treatment planning. By limiting the analysis to patients referred for concurrent chemoradiation, a selection bias toward more fit patients is present. We also recognize that GTV in this series is a mixed parameter composed of pre chemotherapy nodal and post chemotherapy tumor volumes. Nevertheless it provides an estimate of relative disease burden, even though there is a chance that the primary tumor volume can be somewhat influenced by response to the first cycle of chemotherapy.

Despite these limitations, we believe that this study adds to the growing body of evidence supporting the safety and efficacy of selective nodal irradiation for SCLC using FDG PET-CT data. Furthermore, we propose the total GTV as a valuable factor to be investigated for use in future prognostic models.

\section{References}

1. van Meerbeeck JP, Fennell DA, De Ruysscher DK. Small-cell lung cancer. Lancet 2011;378:1741-1755.

2. Sobin LH, Compton CC. TNM seventh edition: what's new, what's changed: communication from the International Union Against Cancer and the American Joint Committee on Cancer. Cancer 116:5336-9.

3. Dehing-Oberije C, Aerts H, Yu S, et al. Development and validation of a prognostic model using blood biomarker information for prediction of survival of non-small-cell lung cancer patients treated with combined chemotherapy and radiation or radiotherapy alone (NCT00181519, NCT00573040, and NCT00572325). Int J Radiat Oncol Biol Phys 2011;81:360-368.

4. Dehing-Oberije C, Yu S, De Ruysscher D, et al. Development and external validation of prognostic model for 2-year survival of nonsmall-cell lung cancer patients treated with chemoradiotherapy. Int $J$ Radiat Oncol Biol Phys 2009;74:355-362.

5. van Loon J, De Ruysscher D, Wanders R, et al. Selective nodal irradiation on basis of (18)FDG-PET scans in limited-disease small-cell lung cancer: a prospective study. Int J Radiat Oncol Biol Phys 2010; 77:329-336.

6. Sobin LH, Wittekind $\mathrm{C}$, and International Union against Cancer. TNM: classification of malignant tumours. New York: Wiley-Liss; 2002. 
7. De Ruysscher D, Pijls-Johannesma M, Bentzen SM, et al. Time between the first day of chemotherapy and the last day of chest radiation is the most important predictor of survival in limited-disease small-cell lung cancer. J Clin Oncol 2006;24:1057-1063.

8. Nijsten SM, Mijnheer BJ, Dekker AL, et al. Routine individualised patient dosimetry using electronic portal imaging devices. Radiother Oncol 2007;83:65-75.

9. van Baardwijk A, Wanders S, Boersma L, et al. Mature results of an individualized radiation dose prescription study based on normal tissue constraints in stages I to III non-small-cell lung cancer. J Clin Oncol 2010;28:1380-1386.

10. Videtic GM, Belderbos JS, Spring Kong FM, et al. Report from the International Atomic Energy Agency (IAEA) consultants' meeting on elective nodal irradiation in lung cancer: small-cell lung cancer (SCLC). Int J Radiat Oncol Biol Phys 2008;72:327-334.

11. De Ruysscher D, Bremer RH, Koppe F, et al. Omission of elective node irradiation on basis of CT-scans in patients with limited disease small cell lung cancer: a phase II trial. Radiother Oncol 2006;80: 307-312.

12. Belderbos JS, Heemsbergen WD, De Jaeger K, et al. Final results of a phase I/II dose escalation trial in non-small-cell lung cancer using three-dimensional conformal radiotherapy. Int J Radiat Oncol Biol Phys 2006;66:126-134.
13. Shirvani SM, Komaki R, Heymach JV, et al. Positron emission tomography/computed tomography-guided intensity-modulated radiotherapy for limited-stage small-cell lung cancer. Int $J$ Radiat Oncol Biol Phys 2012;82:e91-e97.

14. Turrisi AT 3rd, Kim K, Blum R, et al. Twice-daily compared with once-daily thoracic radiotherapy in limited small-cell lung cancer treated concurrently with cisplatin and etoposide. N Engl J Med 1999; 340:265-271.

15. Auperin A, Le Pechoux C, Rolland E, et al. Meta-analysis of concomitant versus sequential radiochemotherapy in locally advanced non-small-cell lung cancer. J Clin Oncol 2012;28:2181-2190.

16. Salem A, Abuodeh Y, Khader J. Selective nodal irradiation on basis of (18) FDG-PET scans in limited-disease small-cell lung cancer: a prospective study. In regard to van Loon et al. (Int J Radiat Oncol Biol Phys 2010;77: 329-336). Int J Radiat Oncol Biol Phys 2010;78:1606-1607.

17. Watkins JM, Wahlquist AE, Zauls AJ, et al. Involved-field radiotherapy with concurrent chemotherapy for limited-stage small-cell lung cancer: disease control, patterns of failure and survival. $J$ Med Imaging Radiat Oncol 2010;54:483-489.

18. Rossi A, Di Maio M, Chiodini P, et al. Carboplatin- or cisplatin-based chemotherapy in first-line treatment of small-cell lung cancer: the COCIS meta-analysis of individual patient data. J Clin Oncol 2012;30: 1692-1698. 